\title{
VERTEBRAL OSTEOMYELITIS IS CHARACTERISED BY INCREASED RANK/OPG AND RANKL/OPG EXPRESSION RATIOS IN VERTEBRAL BODIES AND INTERVERTEBRAL DISCS
}

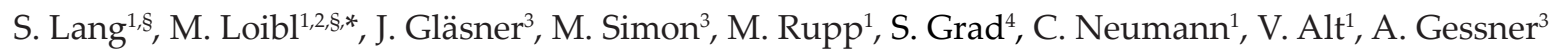 \\ and F. Hanses ${ }^{5,6}$ \\ ${ }^{1}$ Department of Trauma Surgery, University Hospital Regensburg, Franz-Josef-Strauss-Allee 11, \\ 93053 Regensburg, Germany \\ ${ }^{2}$ Department of Spine Surgery, Schulthess Clinic Zurich, Lengghalde 2, 8008 Zurich, Switzerland \\ ${ }^{3}$ Institute of Clinical Microbiology and Hygiene, University Hospital Regensburg, \\ Franz-Josef-Strauss-Allee 11, 93053 Regensburg, Germany \\ ${ }^{4}$ AO Research Institute Davos, Clavadelerstrasse 8, 7270 Davos Platz, Switzerland \\ ${ }^{5}$ Department of Infectious Diseases and Infection Control, University Hospital Regensburg, \\ Franz-Josef-Strauss-Allee 11, 93053 Regensburg, Germany \\ ${ }^{6}$ Emergency Department, University Hospital Regensburg, Franz-Josef-Strauss-Allee 11, \\ 93053 Regensburg, Germany \\ § These authors contributed equally
}

\begin{abstract}
Vertebral osteomyelitis (VO) is an infection of the spine mainly caused by bacterial pathogens. The pathogenesis leading to destruction of intervertebral discs (IVDs) and adjacent vertebral bodies (VBs) is poorly described. The present study aimed at investigating the connection between infection and bone/disc metabolism in $\mathrm{VO}$ patients.

14 patients with VO (infection group) and 14 patients with burst fractures of the spine (fracture group; control) were included prospectively. Tissue biopsies from affected IVDs and adjacent VBs were analysed by RT-qPCR for mRNA-expression levels of 18 target genes including chemokines, adipokines and genes involved in bone metabolism.

Most importantly, the receptor activator of $\mathrm{NF}-\kappa \mathrm{B} /$ osteoprotegerin $(R A N K / O P G)$ expression ratio was drastically elevated in both VBs and IVDs of the infection group. In parallel, expression of genes of the prostaglandin-E2-dependent prostanoid system was induced. Such genes regulate tissue degradation processes via the triad OPG/RANK/RANKL as well as via the chemokines IL-8 and CCL-20, whose expression was also found to be increased upon infection. The gene expression of the adipokine leptin, which promotes inflammatory tissue degradation, was higher in IVD tissue of the infection group, whereas the transcription of omentin and resistin genes, whose functions are largely unknown in the context of infectious diseases, was lower in infected VBs.

In summary, similar expression patterns of pro-inflammatory cytokines and pro-osteoclastogenic factors were identified in VBs and IVDs of patients suffering from VO. This suggests that common immuno-metabolic pathways are involved in the mechanisms leading to tissue degradation in VBs and IVDs during VO.
\end{abstract}

Keywords: Vertebral osteomyelitis, signalling molecules-cytokines, adipokines, cells/tissues-intervertebral disc, infection-in vivo, spine-vertebral body, osteoimmunity, RANK/RANKL/OPG.

*Address for correspondence: PD Dr med Markus Loibl, Department of Trauma Surgery, University Hospital Regensburg, Franz-Josef-Strauss Allee 11, D-93053 Regensburg, Germany.

Telephone number: +49 9419446805 Email: markus.loibl@gmail.com

Copyright policy: This article is distributed in accordance with Creative Commons Attribution Licence (http://creativecommons.org/licenses/by-sa/4.0/). 


\section{List of Abbreviations}

ADAMTS

a disintegrin and metalloprotease with thrombospondin motifs

ADIPOQ adiponectin

AF

annulus fibrosus

$\mathrm{AO}$

BMI

CCI

CCL20

COMI

COX2

CRP

$\mathrm{CT}$

CXCL

DEXA

EQ-5D

ELISA

GUSB

IL

ITLN1

IVD

LEPR

MALDI-TOF matrix-assisted laser desorption/

ionisation-time of flight

MMP

mPEGS1

NAMPT

NP

NSAIDs

ODI

OPG

PCT

PGE2

PPAR- $\gamma$

PROM

QoL

qPCR

RANK

RANKL

RETN

RT-PCR

S. aureus

TLRs

TNF- $\alpha$

$\mathrm{VB}$

$\mathrm{VO}$

Arbeitsgemeinschaft für

Osteosynthesefragen

body mass index

Charlson comorbidity index

chemokine (C-C motif) ligand 20

Core outcome measurement index

cyclooxygenase 2

C-reactive protein

computed tomography

$\mathrm{C}-\mathrm{X}-\mathrm{C}$ motif chemokine ligand

dual-energy $\mathrm{X}$-ray absorptiometry

EuroQoL in 5 dimensions

enzyme-linked immunosorbent

assay

glucuronidase beta

interleukin

intelectin 1 (omentin)

intervertebral disc

leptin

matrix metalloproteinases

microsomal prostaglandin E

synthase 1

nicotinamide

phosphoribosyltransferse (visfatin)

nucleus pulposus

non-steroidal anti-inflammatory

drugs

Oswestry disability index

osteoprotegerin

procalcitonin

prostaglandin E2

peroxisome proliferator-activated

receptor gamma

patient-reported outcome measures

quality of life

quantitative polymerase chain

reaction

receptor activator of nuclear factor $\kappa \mathrm{B}$

RANK ligand

resistin

real-time quantitative polymerase

chain reaction

Staphylococcus aureus

Toll-like-receptors

tumour necrosis factor alpha

vertebral body

vertebral osteomyelitis

\section{Introduction}

Pyogenic VO is defined as an infection of the IVD and adjacent VB and is frequently accompanied by destruction of bone tissue. $\mathrm{VO}$ is the most frequent manifestation of haematogenous osteomyelitis in adults, with an estimated incidence of 2.4 cases per 100,000 people in European countries (Gouliouris et al., 2010; Grammatico et al., 2008). The most common causative pathogen is $S$. aureus, followed by Escherichia coli and Pseudomonas aeruginosa (Doutchi et al., 2015). Several studies have investigated the clinical (Loibl et al., 2014; Mylona et al., 2009), microbiological (Jean et al., 2017; Kim et al., 2015), histological (Iwata et al., 2019) and radiological features (Foreman et al., 2017; Kouijzer et al., 2018) of VO. Nevertheless, the interplay between infection, immune responses and bone/tissue metabolism remains poorly understood. Bone homeostasis and the relation between osteoblasts, osteoclasts and osteocytes are regulated by the RANK/RANKL/ OPG signalling pathway (Wada et al., 2006). RANK and its ligand (RANKL) were first identified in the context of the immune system (Anderson et al., 1997). More than 20 years later, their axis is accepted to be at the interface between bone metabolism and the immune system, thereby forming the basis for the concept of osteoimmunology (Nakashima and Takayanagi, 2009; Okamoto et al., 2017). OPG is a soluble decoy receptor for RANKL, with high affinity. It is expressed by mature osteoblasts and it binds to RANKL, preventing the interaction with its cell surface receptor RANK and inhibiting the production of osteoclasts (Kong et al., 2000). The physiological ratio of RANK/RANKL/OPG is sensitively balanced. An increase in RANKL leads to bone resorption through increased osteoclast formation, function and extended osteoclast survival. On the other hand, OPG plays a bone-protecting role. The RANKL/ OPG ratio has been described as a key determinant of the degree to which osteoclast-mediated bone resorption occurs (Dougall, 2012; Kostenuik, 2005). Bacterial pathogens can stimulate osteoclastogenesis in animal models by inducing RANKL and PGE2, which can potentiate bone resorption, resulting in bone destruction (Meghji et al., 1998; Okahashi et al., 2003; Somayaji et al., 2008). RANKL production by osteoblasts is increased and OPG production decreased following in vitro $S$. aureus infection of both a mouse pre-osteoblastic cell line and human osteoblasts (Widaa et al., 2012; Young et al., 2011). Furthermore, $S$. aureus interaction with osteoblasts stimulates the expression of many chemokines (e.g. CXCL8, CXCL10), cytokines (e.g. IL1 $\beta$, IL18, TNF- $\alpha$, IL6, IL12), COX2 and important growth factors (Josse et al., 2015). IL8 as well as the T- and B-cell-attracting cytokine CCL20, both induced by the action of PGE2 on T cells (Boniface et al., 2009; Caristi et al., 2005; Chizzolini et al., 2008), enhance osteoclastogenesis through modulation of cytokine production by human primary osteoblasts (Pathak et al., 2015).

In contrast to the well-vascularised VB, the IVD, consisting of the NP, AF and cartilage-like endplate, is an avascular, immune-privileged organ. This may be a reason why comprehensive exploration of the immunological mechanisms in the infected 
Table 1. Primer sequences for 18 target genes and the reference GUSB used for qPCR.

\begin{tabular}{|c|c|c|}
\hline Gene & Gene symbol & Sequence $\left(5^{\prime}\right.$ to $\left.3^{\prime}\right)$ \\
\hline \multirow{2}{*}{ Glucuronidase beta } & \multirow{2}{*}{ GUSB } & GAAAATACGTGGTTGGAGAGCTCATT \\
\hline & & CCGAGTGAAGATCCCCTTTTTA \\
\hline \multirow{2}{*}{ RANK } & \multirow{2}{*}{ TNFRSF11A } & ATGCGGTTTGCAGTTCTTCTC \\
\hline & & АСТССТTATСТССАСТTAGG \\
\hline \multirow{2}{*}{ RANKL } & \multirow{2}{*}{ TNFSF11 } & CACTATTAATGCCACCGAC \\
\hline & & GGGTATGAGAACTTGGGATT \\
\hline \multirow{2}{*}{ OPG } & \multirow{2}{*}{ TNFRSF11B } & GCTTGAAACATAGGAGCTG \\
\hline & & GTTTACTTTGGTGCCAGG \\
\hline \multirow{2}{*}{ Leptin } & \multirow{2}{*}{$L E P R$} & CAAGCTGTGCCCATCCAAAA \\
\hline & & GGATCACGTTTCTGGAAGGC \\
\hline \multirow{2}{*}{ Resistin } & \multirow{2}{*}{ RETN } & TCGCCGGCTCCCTAATATTT \\
\hline & & ACTGGCAGTGACATGTGGT \\
\hline \multirow{2}{*}{ Adiponectin } & \multirow{2}{*}{ ADIPOQ } & GAGATCCAGGTCTTATTGGTC \\
\hline & & CTTTCCTGCCTTGGATTCC \\
\hline \multirow{2}{*}{$\begin{array}{c}\text { Nicotinamide } \\
\text { phosphoribosyltransferase (visfatin) }\end{array}$} & \multirow{2}{*}{ NAMPT } & GAGTTCAACATCCTCCTGGC \\
\hline & & TCACGGCATTCAAAGTAGGA \\
\hline \multirow{2}{*}{ Intelectin 1 (omentin) } & \multirow{2}{*}{ ITLN1 } & ACTGCGGGATTTGTTCAGTT \\
\hline & & GTATCCTCCTCCACCAATGC \\
\hline \multirow{2}{*}{$\begin{array}{l}\text { COX2 /prostaglandin-endoperoxide } \\
\text { synthase-2 }\end{array}$} & \multirow{2}{*}{ PTGS2 } & CTCCTGTGCCTGATGATTGC \\
\hline & & TCTAGCCAGAGTTTCACCGT \\
\hline \multirow{2}{*}{$\begin{array}{l}\text { Microsomal prostaglandin E } \\
\text { synthase- } 1\end{array}$} & \multirow{2}{*}{$\begin{array}{c}\text { PTGES } \\
(m P G E S 1)\end{array}$} & GAGACACGGAGGCCCCCAGTATTG \\
\hline & & GCCCGCAGCTTCCCCAGGTAG \\
\hline \multirow{2}{*}{$\begin{array}{l}\text { Peroxisome proliferator activated } \\
\text { receptor gamma (PPAR-g) }\end{array}$} & \multirow{2}{*}{ PPARG } & GGGGTTCTCATATCCGAGGG \\
\hline & & GGGCGGTCTCCACTGAGAATAA \\
\hline \multirow{2}{*}{ CCL1 } & \multirow{2}{*}{ CXCL1 } & AAGTGTGAACGTGAAGTCC \\
\hline & & GGATTTGTCACTGTTCAGCA \\
\hline \multirow{2}{*}{ CCL5 } & \multirow{2}{*}{ CXCL5 } & GGAAGGAAATTTGTCTTGATCC \\
\hline & & TTTCCTTGTTTCCACCGTC \\
\hline CCI 8 & CYCI \& (II \&) & GGCAGCCTTCCTGATTTCTGCAGC \\
\hline CCLO & $\operatorname{CXCL8}(1 L 8)$ & GTTTTCCTTGGGGTCCAGACAGAGC \\
\hline$C C \mathrm{I} 10$ & $C Y C \rightarrow$ & TTCAAGGAGTACCTCTCTCTAG \\
\hline CCLIU & $\operatorname{C} \times C L I O$ & CTGGATTCAGACATCTCTTCTC \\
\hline מי חמ זר & & TGCTGTACCAAGAGTTTGCTC \\
\hline CCL20 & $C(L 20(M I P-3 a)$ & CGCACACAGACAACTTTTTCTTT \\
\hline MMP12 & $M M P 12$ & CTGCATCCTCAGCAGGTTG \\
\hline IVIVII 13 & IVIVIP13 & GTCTCGGATAGTCTTTATCC \\
\hline & & CAAGGTCCCATGTGCAACGT \\
\hline ADAMTS4 & ADAMTS4 & CATCTGCCACCACCAGTGTCT \\
\hline
\end{tabular}

IVD remains challenging. On the other hand, the degenerated IVD has been studied in detail. In degenerative discs, tissue-degrading enzymes such as MMPs, ADAMTSs and TLRs are induced (Bachmeier et al., 2009; Kepler et al., 2013; Klawitter et al., 2014; Millward-Sadler et al., 2009). Interestingly, the RANK/RANKL/OPG system has also been shown in ex vivo studies of human IVD tissue to be involved in IVD degeneration (Sano et al., 2019; Takegami et al., 2017). To the authors' knowledge, there have been no studies investigating the role of the RANK/ RANKL/OPG system in conditions of VO. For this reason, mRNA expression patterns were investigated in tissue samples from IVDs and adjacent VBs of patients suffering from $\mathrm{VO}$ and vertebral fractures (control patients). Candidate genes were selected to provide an overview of basic bone metabolism and inflammation. Moreover, genes previously implicated in bacterial infection were analysed. The study hypothesis was that the RANK/RANKL/ OPG axis as well as key immune-regulatory (adipo-) cytokines and proteinases are affected by VO.

\section{Materials and Methods}

\section{Patients}

The study prospectively included patients suffering from clinically and radiologically confirmed native pyogenic $\mathrm{VO}$ who were treated at the University 
Hospital Regensburg, Germany between 2013 and 2015 (infection group). Patients suffering postoperative, implant-associated infection, tuberculosis, chronic inflammatory diseases and solid tumours were not included in the study. Patient-related data (gender, age, BMI) and treatment details (surgical strategy, duration of hospitalisation, treatment with NSAIDs and antibiotics) were recorded and the $\mathrm{CCI}$ (Charlson et al., 1987) was assessed for each patient in the infection group based on the medical history. PROM before surgery and at least 12 months postoperatively were recorded: for the evaluation of the QoL outcomes, the well-established COMI (Mannion et al., 2009) and the ODI (Fairbank and Pynsent, 2000) were used. Laboratory parameters (CRP, leukocyte count, PCT) were measured as part of routine controls and documented at 5 different time points: (i) admission to the hospital, (ii) the week before surgery, (iii) the day before surgery, (iv) discharge, (v) last followup. In patients with two-stage surgical procedures, the corpectomy (second surgery) was chosen as a reference point.

As a control (fracture) group, patients that received stabilisation of the anterior spinal column for the treatment of burst fractures at the University Hospital Regensburg, Germany between 2013 and 2015 were prospectively included in the study.

\section{Ethics statement}

This study was carried out in accordance with the Declaration of Helsinki and approved by the ethics committee at the University of Regensburg (Institutional Review Board number 12-101-0218). Written informed consent was obtained from all individual participants included in the study.

\section{Tissue samples}

Tissue samples from the VB and IVD were collected from all patients in both groups either by CT-guided biopsy or open surgical biopsy. Intraoperatively, the area of interest at the infected VB and IVD was identified and samples were obtained as part of the necessary debridement of the infected segment. In fracture patients, the fractured VB was removed (partial/complete), together with the affected IVD, before the anterior column reconstruction, using an iliac crest bone graft (mono-segmental) or an expandable vertebral body replacement (bisegmental). Biopsies of VB and IVD were harvested intra-operatively, placed in $500 \mu \mathrm{L}$ RNAlater solution (Ambion) and stored at $4^{\circ} \mathrm{C}$ overnight to allow the solution to thoroughly penetrate into the tissue. Next, they were stored at $-20^{\circ} \mathrm{C}$ until processing.

\section{Microbiology}

In patients of the infection group, pathogens were detected in blood cultures $(n=5)$, in CT-guided biopsies of either the VB $(n=1)$ or IVD $(n=2)$, or in intraoperative open biopsies of either the VB $(n=11)$ or IVD $(n=11)$. Cultured isolates were identified using MALDI-TOF mass spectrometry using a Microflex LT device and BioTyper software (Bruker Daltonik, Bremen, Germany). In one case, culture was negative; however, a specific pSa-442 PCR (Reischl et al., 2000) detected S. aureus in the VB as well as in the IVD biopsy.

\section{mRNA isolation and cDNA synthesis}

Total RNA was isolated from preserved tissue samples using the RNAqueous Total RNA Isolation kit (Ambion). Tissue samples were disrupted and homogenised in the Lysis/Binding solution provided with the kit by using a $5 \mathrm{~mm}$ stainless steel bead and a TissueLyser (Qiagen) for 6-8 $\mathrm{min}$ at $30 \mathrm{~Hz}$. Isolated RNA was treated using the TURBO DNA-free kit (Invitrogen) to remove genomic DNA. Purified RNA was quantified using a NanoDrop 1000 and the quality analysed using an Agilent Bioanalyzer 2100. Approximately $300 \mathrm{ng}$ of total RNA per sample were used for reverse transcription using the iScript Advanced cDNA Synthesis Kit (Bio-Rad).

\section{qRT-PCR}

Absolute quantification of transcripts was done by qPCR using a TaqMan ABI 7900HT system (Applied Biosystems) and SYBR Green I. Amplification was carried out in duplicates over 45 cycles of $10 \mathrm{~s}$ at $95^{\circ} \mathrm{C}$, $15 \mathrm{~s}$ at $55-61^{\circ} \mathrm{C}$ and $15 \mathrm{~s}$ at $72^{\circ} \mathrm{C}$. In each qPCR run, an external standard curve was generated using a 5 Log-spanning serial dilution of the pGEM $^{\circledR}$-T Easy plasmid vector (Web ref. 1) harbouring one copy of the respective target sequence per plasmid molecule. qPCR was performed in a reaction volume of $10 \mu \mathrm{L}$ containing $5 \mu \mathrm{L}$ of LightCycler 480 SYBR Green I Master (Roche), $0.4 \mu \mathrm{mol} / \mathrm{L}$ of each primer (Table 1) and $2 \mu \mathrm{L}$ of the cDNA sample in a 5 -fold dilution. Calculated copy numbers of the target genes were normalised to $10^{5}$ copies of the reference gene GUSB. A second reference gene (beta-2-microglobulin) was used to cross-check and to verify the obtained results. Specificity of products was assessed by highresolution melting curves.

\section{Statistical analysis}

Statistical analysis was carried out using $\mathrm{R}$ version 3.6.2 (R Core Team, Vienna, Austria). Figures were designed using the $\mathrm{R}$ packages 'ggplot2', 'ggpubr' and 'corrplot'. Variables were tested for normal distribution using the Shapiro-Wilk test. Groups were compared using Mann-Whitney U tests. Spearman's rank coefficient tests were used to evaluate the degree of correlation of gene expression levels in VB and IVD and to evaluate the degree of correlation of gene expression levels and clinical parameters, separately for the infection group and for the fracture group. Differences in PROM between groups and time points were evaluated using the independent and dependent paired $t$-test, respectively. $p<0.05$ was considered statistically significant. 
Table 2. Demographic, treatment details and PROMs of the infection group $(n=14)$ compared to the fracture group $(n=14)$. Variables are given in absolute number or mean \pm standard deviations. Significance was assessed by chi-squared test for frequencies of anti-inflammatory drug and preoperative antibiotic intake and deaths and by independent $t$-test for the hospitalisation time and the PROM results. $p$ values indicated in bold are statistically significant.

\begin{tabular}{|c|c|c|c|c|}
\hline & Parameter & Infection group $(n=14)$ & Fracture group $(n=14)$ & $p$ \\
\hline \multirow{3}{*}{ Demographics } & Age (years) & $67.1 \pm 11.7(44.0-81.0)$ & $42.7 \pm 13.5(22.0-68.0)$ & 0.000 \\
\hline & Sex (male) & $n=9$ & $n=12$ & 0.284 \\
\hline & $\mathrm{BMI}\left(\mathrm{kg} / \mathrm{m}^{2}\right)$ & $30.5 \pm 6.0$ & $23.7 \pm 3.4$ & 0.002 \\
\hline \multirow{4}{*}{ Treatment } & Hospitalisation $(\mathrm{d})$ & $28.4 \pm 12.8$ & $19.3 \pm 8.1$ & 0.043 \\
\hline & $\begin{array}{c}\text { Antiinflammatory drugs } \\
\text { preoperative (yes) }\end{array}$ & $n=10$ & $n=14$ & 0.034 \\
\hline & Antibiotics preoperative (yes) & $n=10$ & $n=0$ & 0.001 \\
\hline & Deaths during follow-up (yes) & $n=2$ & $n=0$ & 0.150 \\
\hline \multirow{4}{*}{ PROM } & ODI preoperative & $59.7 \pm 21.5$ & $82.7 \pm 10.3$ & 0.030 \\
\hline & ODI follow-up & $20.8 \pm 18.4$ & $26.7 \pm 13.5$ & 0.424 \\
\hline & COMI preoperative & $6.8 \pm 2.0$ & $8.4 \pm 2.4$ & 0.213 \\
\hline & COMI follow-up & $2.3 \pm 2.3$ & $1.7 \pm 1.6$ & 0.875 \\
\hline
\end{tabular}

\section{Results}

\section{Demographics and treatment details}

28 patients were included in the study, with 14 patients in the infection group (infection group) and 14 patients in the control group (fracture group). Intraoperative tissue samples from the affected VB and IVD were collected from all patients after written informed consent was obtained. 14 patients (5 females, 9 males) with clinical and radiological proof of $\mathrm{VO}$ in whom a causative pathogen was identified were evaluated. In the fracture group, all tissue samples needed for mRNA isolation were collected from the VB $(n=11)$ and IVD $(n=11)$ by intraoperative open biopsy.

The mean age of patients in the infection group was $67.1 \pm 11.7(44-81)$ years. The mean BMI was $30.5 \pm 6.1 \mathrm{~kg} / \mathrm{m}^{2}$. The median CCI was $3.5(0-8)$. $\mathrm{VO}$ was located in the cervical spine in 3 cases, the thoracic spine in 4 cases, the lumbar spine in 6 cases and 1 patient suffered from multifocal $\mathrm{VO}$ of the cervical, thoracic and lumbar spine. The mean CRP value at admission (i) was $84.0 \pm 62.9 \mathrm{mg} / \mathrm{L}$ and reached $129.3 \pm 74.1 \mathrm{mg} / \mathrm{L}$ in the week before surgery (ii). The day before surgery (iii), $87.6 \pm 60.4 \mathrm{mg} / \mathrm{L} \mathrm{CRP}$ was measured. The CRP value at discharge (iv) was $40.5 \pm 44.8 \mathrm{mg} / \mathrm{L}$ and decreased to $9.0 \pm 9.6 \mathrm{mg} / \mathrm{L}$ at the last follow-up (v). CRP-values at discharge (iv) and at the last follow-up (v) were significantly lower compared to the values at admission (i; $p<0.001$ and $p=0.020$, respectively). Both values (iv and v) were also significantly lower compared to the highest CRP values (the week before surgery, ii) ( $p=0.010$ and $p=0.010$, respectively). Furthermore, treatment success was monitored using the QoL analysis and patients in the infection group were followed for $18.2 \pm 5.3$ months. The mean ODI and COMI improved significantly from preoperative values to the follow-up ( $p=0.003$ and $p=0.001$, respectively; Table 2).
The mean age of the patients in the fracture group was $42.7 \pm 13.5(22-68)$ years. The mean BMI was $23.7 \pm 3.4 \mathrm{~kg} / \mathrm{m}^{2}$. The most frequently seen fracture morphology was the AO type A2 fracture $(n=6)$, followed by A3 $(n=4)$ and A4 $(n=4)$. In 4 cases an additional flexion-distraction injury (AO type B2) was documented. Fractures were found at the thoracolumbar transition in 13 cases (Th11: $n=6$; Th12/L1: $n=1$; L1: $n=6$ ). The cervical spine was affected in 1 case. The mean time between the trauma and the stabilisation surgery for the anterior column with biopsy was $7.4 \mathrm{~d}$ (range 1-18 d). Results of the ODI and COMI values of patients in the fracture group are listed in Table 2.

\section{Therapy with anti-inflammatory drugs and antibiotics}

All patients in the infection group received antibiotic treatment during hospitalisation. Treatment was started before surgery for 12 patients (Table 2). The most frequently pre-operatively used antibiotics (and combinations thereof) were rifampicin in 7 cases (mean: $14.6 \mathrm{~d}$; range: 5-31 d), flucloxacillin in 3 cases (mean: $13.7 \mathrm{~d}$; range: 6-23 d), cefazolin in 2 cases (mean: $8.5 \mathrm{~d}$; range: $4-13 \mathrm{~d}$ ) and meropenem in 2 cases (mean: $31.5 \mathrm{~d}$; range: $8-55 \mathrm{~d}$ ). Ciprofloxacin (18 d), linezolid $(4 \mathrm{~d})$, levofloxacin $(9 \mathrm{~d})$ or metronidazol (5 d) ware used in 1 case each.

In the infection group, 10 out of 14 patients took anti-inflammatory drugs at the time of biopsy, most frequently metamizol $(n=5)$ and ibuprofen $(n=5)$ (Table 2). All patients in the fracture group received anti-inflammatory drugs preoperatively, most frequently metamizol $(n=10)$ and ibuprofen $(n=10)$.

\section{Causative pathogens and severity of VO}

$S$. aureus was identified as the causative pathogen in 8 patients. Staphylococcus epidermidis was found in 2 cases. In 1 case each Pseudomonas aeruginosa, Enterococcus faecium, Propionibacterium avidum and 
Achromobacter spp. were identified. Blood cultures were positive in 5 cases (all $S$. aureus). 4 patients were diagnosed with (concomitant) sepsis. In 5 cases a psoas and/or an epidural abscess were found. 1 patient was diagnosed with endocarditis.

Most VO-associated complications were seen in patients with $S$. aureus infection: 4 out of 5 epidural abscesses, 4 out of 5 psoas abscesses and 1 out of 1 endocarditis were found in these patients. Patients infected with $S$. aureus had also a significant higher CRP value at admission $(122.5 \pm 56.9 \mathrm{mg} / \mathrm{L})$ than the other patients in the infection group $(32.6 \pm 13.9 \mathrm{mg} / \mathrm{L})$ $(p=0.03)$.

\section{Transcriptional changes at infected sites in VO}

To provide an overview of changes in basic bone metabolism and tissue degradation in a VO setting, mRNA expression of RANK, RANKL, OPG and proteases were measured (Fig. 1).

OPG mRNA expression was significantly lower in $\operatorname{VB}\left(3.3 \times 10^{3} \pm 3.4 \times 10^{3}\right)$ and showed a trend towards lower expression in IVD $\left(7.2 \times 10^{3} \pm 7.1 \times 10^{3}\right)$ tissue samples in the infection group compared to the fracture group (VB: $2.6 \times 10^{4} \pm 2.4 \times 10^{4}, p=0.003$; IVD: $\left.7.9 \times 10^{4} \pm 9.5 \times 10^{4}, p=0.097\right)$. In the infection group, $R A N K$ expression in the VB was significantly higher $\left(8.4 \times 10^{3} \pm 7.4 \times 10^{3}\right)$ and with a trend towards a higher expression in IVDs $\left(6.4 \times 10^{3} \pm 5.9 \times 10^{3}\right)$ than in the fracture group (VB: $2.9 \times 10^{3} \pm 2.6 \times 10^{3}$, $p=0.034$; IVD: $\left.9.2 \times 10^{2} \pm 8.5 \times 10^{2}, p=0.097\right)$. There was no significant difference in $R A N K L$ mRNA expression in VBs (infection: $1.7 \times 10^{4} \pm 2.8 \times 10^{4}$; fracture: $1.6 \times 10^{4} \pm 1.8 \times 10^{4}$ ) and IVDs (infection: $1.7 \times 10^{4} \pm 1.6 \times 10^{4}$; fracture: $\left.1.0 \times 10^{4} \pm 9.2 \times 10^{3}\right)$ between both groups (Fig. 1).

$m P E G S 1$ was significantly upregulated in IVDs $\left(5.9 \times 10^{4} \pm 7.8 \times 10^{4}, p=0.026\right)$ and with a tendency towards upregulation in $\operatorname{VBs}\left(4.1 \times 10^{4} \pm 7.4 \times 10^{4}\right.$, $p=0.068)$ of the infection group compared to the fracture group (IVD: $5.3 \times 10^{3} \pm 3.2 \times 10^{3}$; VBs: $1.5 \times 10^{4} \pm 3.2 \times 10^{4}$ ) (Fig. 1). COX2 mRNA expression showed a trend towards a higher expression in VBs $\left(8.0 \times 10^{3} \pm 8.3 \times 10^{3}\right)$ and IVDs $\left(9.3 \times 10^{3} \pm 1.8 \times 10^{4}\right)$ of the infection group compared to the fracture group (VB: $5.7 \times 10^{3} \pm 1.4 \times 10^{4}, p=0.064$; IVD: $\left.2.8 \times 10^{3} \pm 1.2 \times 10^{3}, p=0.566\right)$.

Among the proteases, only ADAMTS4 was found to be upregulated in VBs of the infection group (infection: $1.3 \times 10^{5} \pm 2.5 \times 10^{5}$; fracture: $\left.3.1 \times 10^{4} \pm 4.3 \times 10^{4} ; p=0.022\right) . P P A R-\gamma$ was significantly downregulated in VBs of the infection group (infection: $7.3 \times 10^{3} \pm 6.4 \times 10^{3}$; fracture: $1.4 \times 10^{4} \pm 8.7 \times 10^{3}$; $p=0.007$ ), whereas no significant difference was seen in the IVDs (infection: $6.4 \times 10^{3} \pm 5.5 \times 10^{3}$; fracture: $\left.1.1 \times 10^{4} \pm 3.6 \times 10^{3} ; p=0.138\right)$. The protease MMP13 showed a trend towards a higher mRNA expression in VBs $\left(1.6 \times 10^{6} \pm 3.5 \times 10^{6}\right)$ and IVDs $\left(8.2 \times 10^{5} \pm 9.4 \times 10^{5}\right)$ in the infection group compared

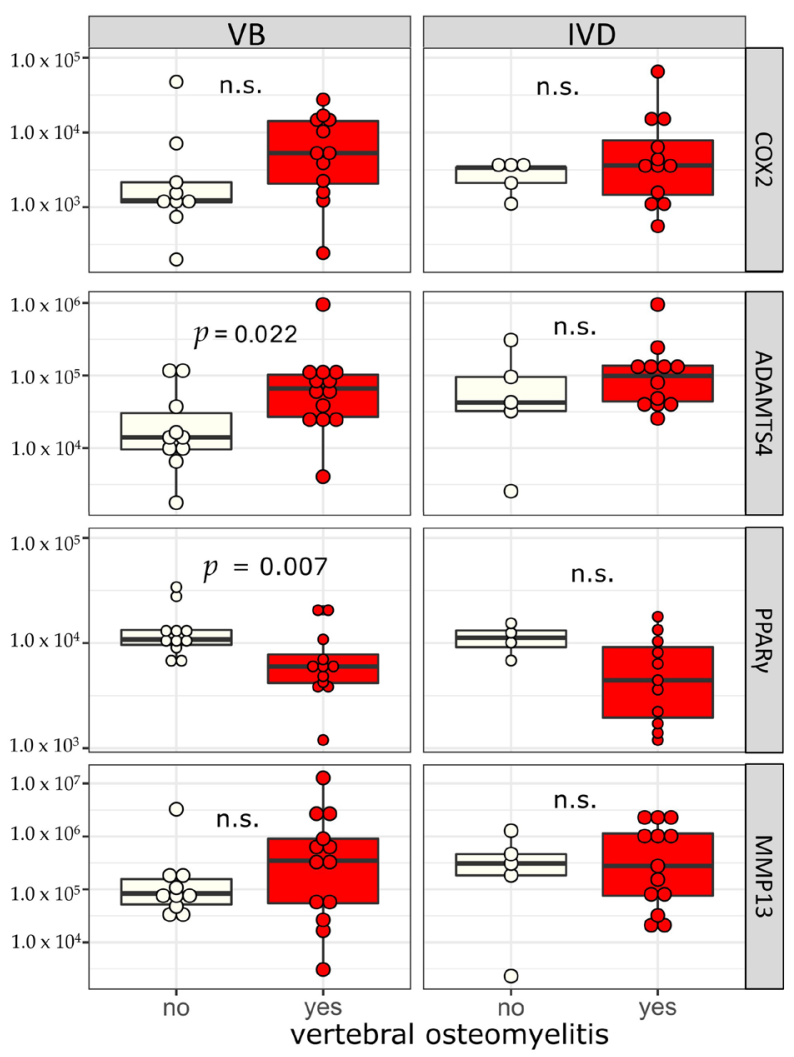

Fig. 1. Comparison between mRNA expressions of (bone) metabolic genes in fracture (beige) and infection group (red) in VBs and IVDs. The infection group is indicated by "yes" (VO), the fracture group by "no" (no VO). Depicted are copy numbers of each target gene normalised to $10^{5}$ copies of GUSB. Boxes represent the interquartile range with indicated median. Significance was assessed by Mann-Whitney U test. n.s: statistically not significant. 


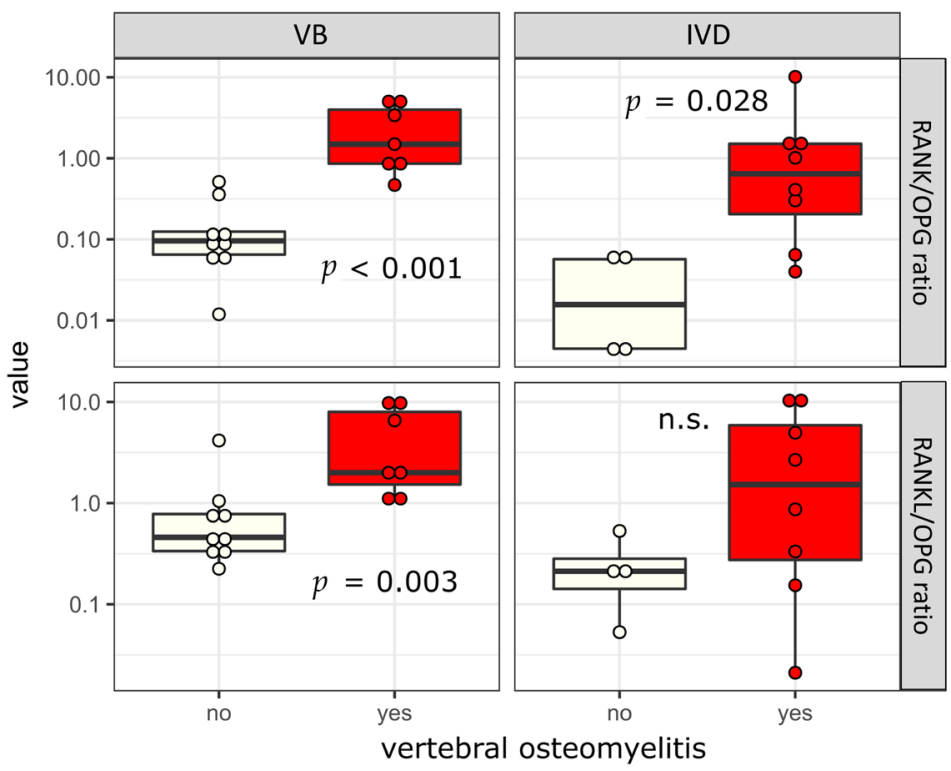

Fig. 2. Comparison between the calculated $R A N K / O P G$ and $R A N K L / O P G$ expression ratios in fracture (beige) and infection group (red) in VBs and IVDs. The infection group is indicated by "yes" (VO), the fracture group by "no" (no VO). Significance was assessed by Mann-Whitney U tests. n.s: statistically not significant.

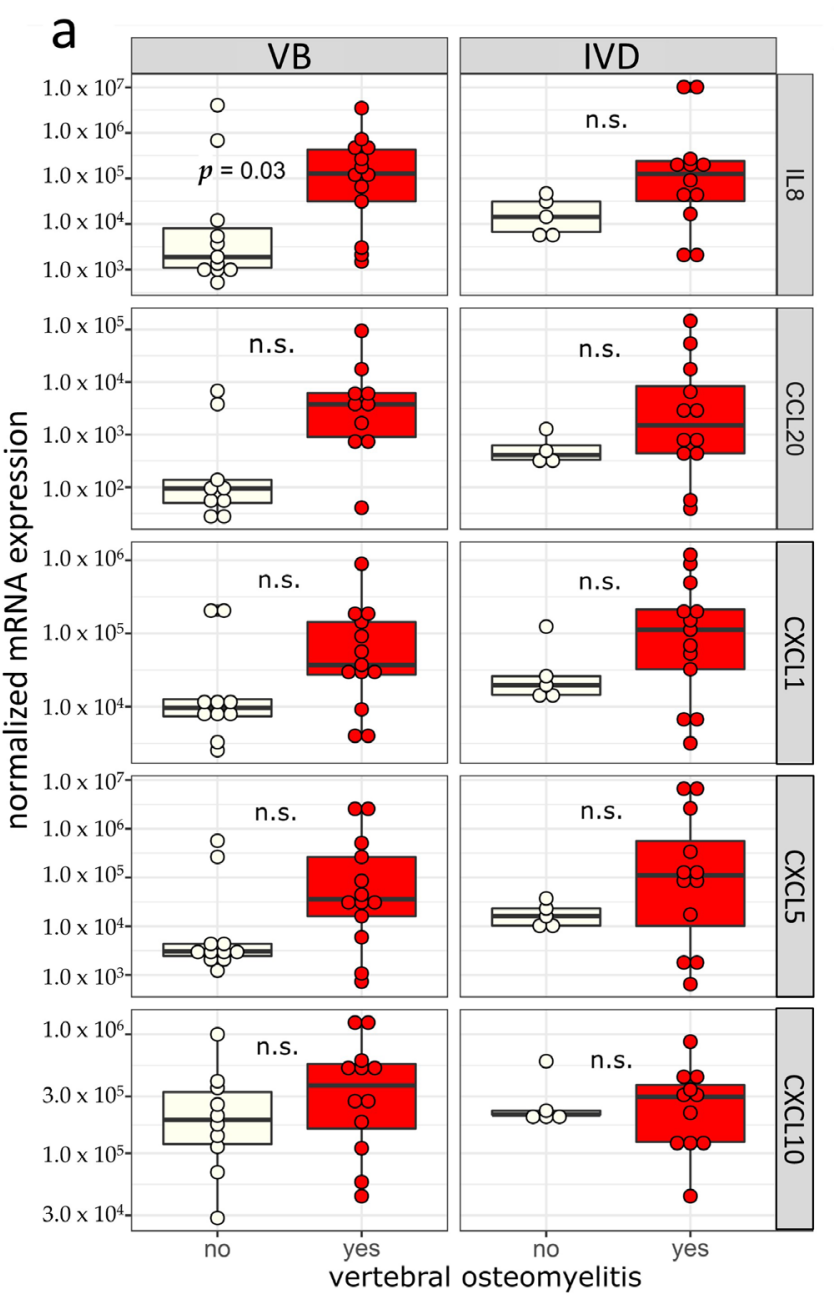

b

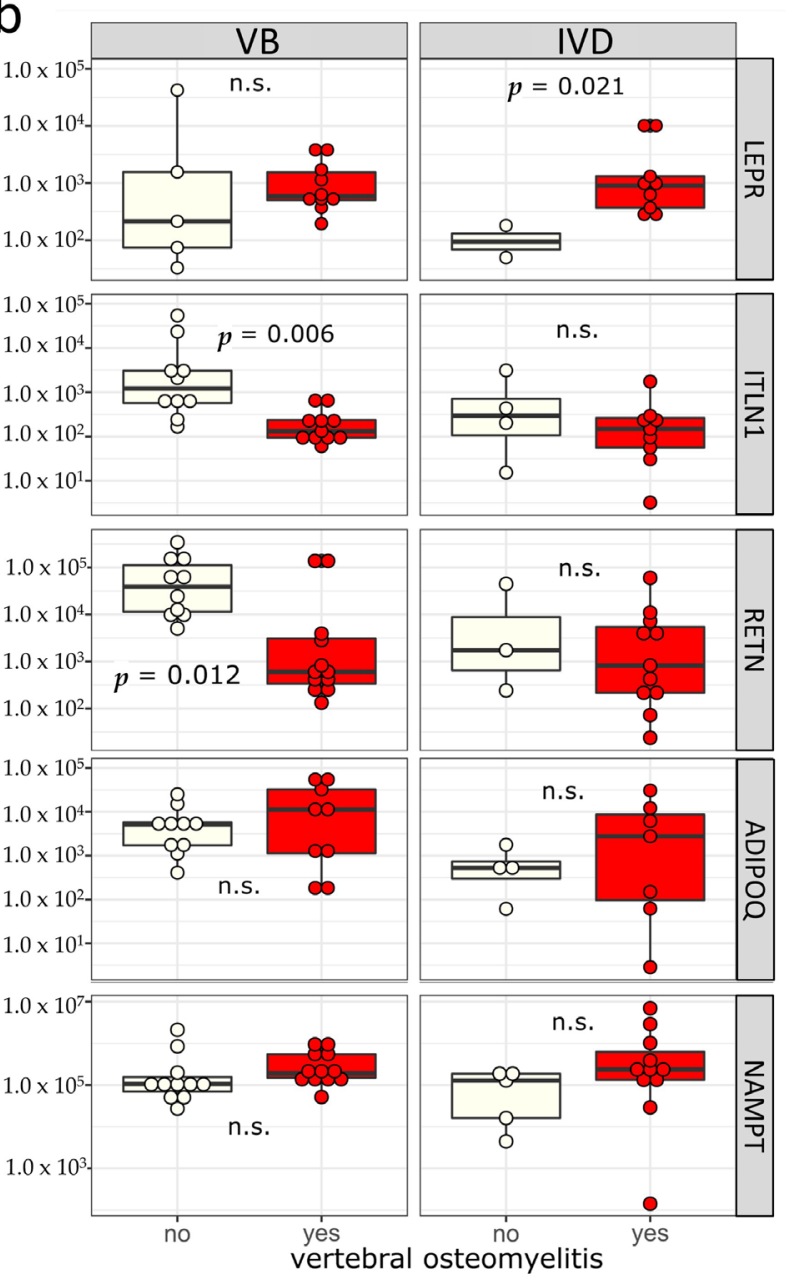

Fig. 3. (a) Comparison between the mRNA expressions of cytokines in the fracture (beige) and infection group (red) in VBs and IVDs. (b) Comparison between the mRNA expression of pro- and antiinflammatory adipokines in VBs and IVDs. The infection group is indicated by "yes" (VO), the fracture group by "no" (no VO). Depicted are copy numbers of each target gene normalised to $10^{5}$ copies of GUSB. Boxes represent the interquartile range with indicated median. Significance was assessed by Mann-Whitney U tests. n.s: statistically not significant. 
to the fracture group (VB: $3.7 \times 10^{5} \pm 9.6 \times 10^{5}, p=0.252$; IVD: $\left.4.5 \times 10^{5} \pm 5.0 \times 10^{5}, p=0.849\right)$.

The mean $R A N K / O P G$ ratio was significantly higher in both compartments in the infection group (VB: $2.5 \pm 2.0, p<0.001$; IVD: $1.9 \pm 3.4, p=0.028$ ) compared to the fracture group (VB: $0.2 \pm 0.2$; IVD: $0.0 \pm 0.0$; Fig. 2). Similarly, the mean RANKL/OPG ratio was significantly higher in VBs $(4.6 \pm 4.0)$ and also with a trend towards a higher expression in IVDs $(3.7 \pm 4.4)$ of the infection group compared to the fracture group (VB: $0.9 \pm 1.2, p=0.003$; IVD: $0.3 \pm 0.2$, $p=0.214)$.

To assess the role of osteoclastogenesis-enhancing chemokines, the mRNA expressions of IL8 and CCL20 were measured (Brylka and Schinke, 2019; Pathak et al., 2015). Furthermore, the mRNA expressions of the neutrophil-attracting chemokines CXCL1 and CXCL5 were measured (Fig. 3a). Neutrophils are, on the one hand, key elements in the cellular defence against bacterial infection and, on the other hand, they play a critical role in bacteria-induced apoptosis and/or in phagocytosis-induced cell death (Asensi et al., 2017).

Compared to tissues samples from fracture patients, IL8 expression was significantly higher (infection: $4.6 \times 10^{5} \pm 9.4 \times 10^{5}$; fracture: $4.3 \times 10^{5} \pm 1.2 \times 10^{6}$; $p=0.03$ ) and CCL20 showed a trend towards a higher expression (infection: $1.0 \times 10^{4} \pm 2.6 \times 10^{4}$; fracture: $\left.1.0 \times 10^{3} \pm 2.2 \times 10^{3} ; p=0.181\right)$ in VB tissue in the infection group. Chemokine expression in IVDs as well as CXCL1, CXCL5 and CXCL10 expression in VBs and IVDs showed only a trend towards a higher expression in the infection group compared to the fracture group (Fig. 3a).

Changes in the transcription profile of the proinflammatory adipokines LEPR, ADIPOQ and
NAMPT as well as of the adipokines ITLN1 and RETN, whose functions in infectious diseases are scarcely described, were evaluated to shed light into their role in inflammatory processes potentially contributing to tissue degradation in VO. From the adipokine group, the pro-inflammatory LEPR showed a significantly higher expression in IVD tissue samples in the infection group (infection: $2.3 \times 10^{3} \pm 3.9 \times 10^{3}$; fracture: $4.6 \times 10 \pm 7.8 \times 10 ; p=0.021)$, whereas ITLN1 and RETN were significantly lower expressed in VB tissue of the infection group (ITLN1: $2.0 \times 10^{2} \pm 2.2 \times 10^{2} ; p=0.006$; RETN: $\left.2.2 \times 10^{4} \pm 5.2 \times 10^{4} ; p=0.012\right)$ compared to the fracture group (ITLN1: $8.0 \times 10^{3} \pm 1.7 \times 10^{4}$; RETN: $\left.7.6 \times 10^{4} \pm 1.1 \times 10^{5}\right)$ (Fig. 3b). The pro-inflammatory $A D I P O Q$ and NAMPT showed trends towards a higher expression in IVD and VB of the infection group compared to the fracture group (all $p \geq 0.05$; Fig. 3b).

Fig. 4 provides a graphical summary of hypothetical regulatory pathways leading to tissue degradation in bacterial VO, considering the local transcriptional changes identified in the present study.

Correlation between mRNA expression levels and preoperative clinical parameters

To identify potential concordant or discordant expression patterns between the above-mentioned genes and preoperative clinical parameters $1 \mathrm{~d}$ before surgery (iii), correlations in the infection group were visually analysed using a correlogram by tissue type (Fig. 5).

A positive correlation between the VB mRNA expression of PPAR- $\gamma$ and the expression of ADIPOQ and CXCL10 as well as the CRP value at the time of surgery (iii) was found (Fig. 5, bone). Similarly,

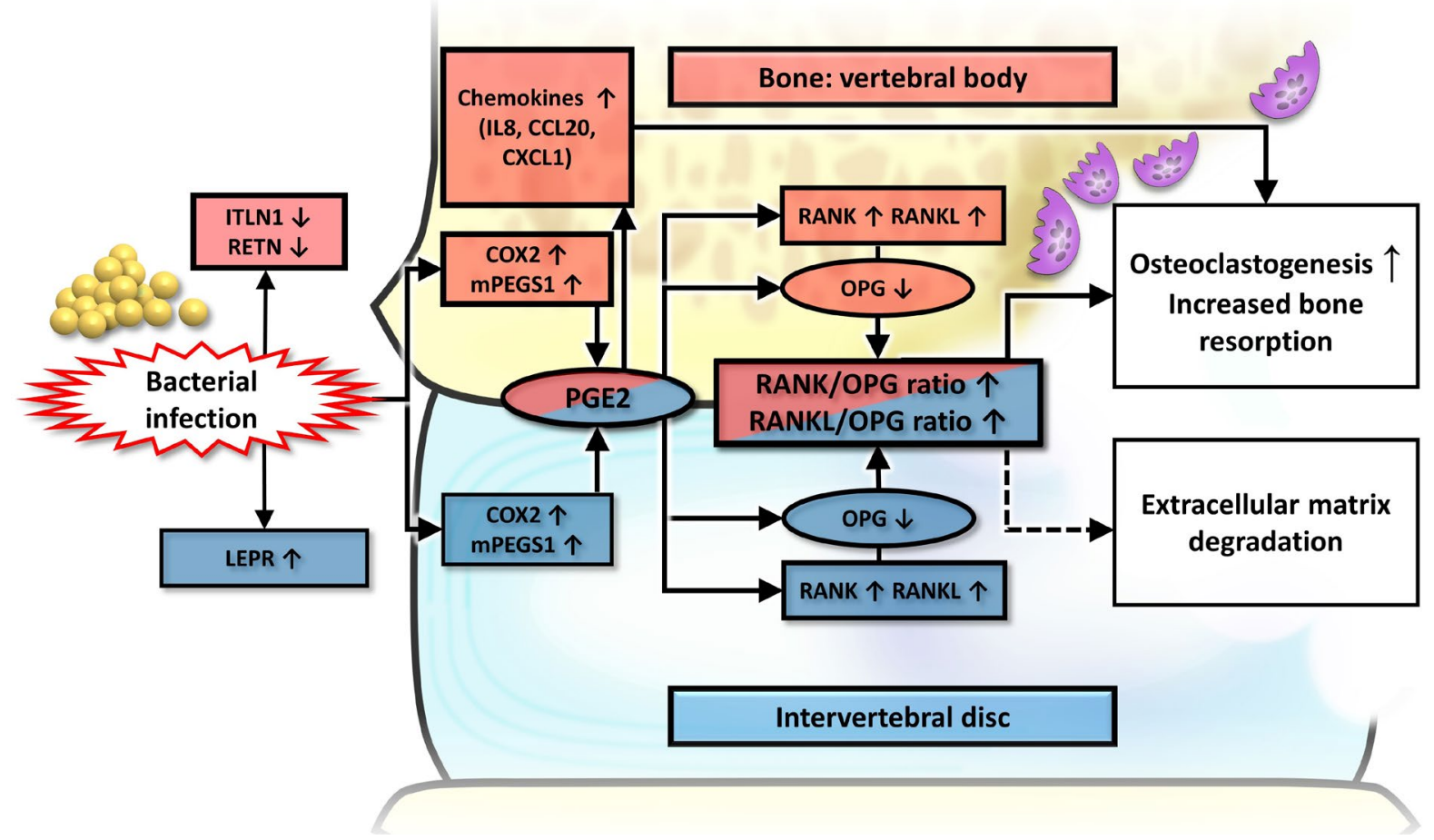

Fig. 4. Graphical summary of hypothetical regulatory pathways leading to tissue degradation in bacterial VO, considering local transcriptional changes identified in the present study. The mRNA regulations are illustrated separately for the VB (red) and IVD (blue). 
a positive correlation between COX2 and CCL2O expression in VBs was seen (Fig. 5, bone). In the IVDs of the infection group a positive correlation between mPGES-1 as well as COX2 expression and IL8, CXCL1, CXCL5 and CCL20 expression was detected (Fig. 4, disc). In infected IVD tissue, the mRNA expression levels of the T-cell- and macrophage-attracting chemokine CXCL10 and of OPG showed negative correlations with the expression of COX2, mPEGS1, NAMPT, CXCL1, CXCL5, IL8 and CCL20 (Fig. 5, disc). Among others, the PCT value at the time of surgery (iii) was negatively correlated with the expression of ADAMTS4, RANK, RANKL and MMP13 of infected IVDs (Fig. 5, disc).

\section{Case-specific alterations to mRNA expressions}

To evaluate whether mRNA expressions were altered in the VB and IVD depending on the donor, Spearman correlation coefficients were calculated for the expression levels in VB and IVD separately for the infection and fracture groups.

In the infection group, MMP13 mRNA expression showed a statistically significant positive Spearman correlation between VB and IVD samples $(\rho=0.827$; $p=0.002)$. Also, CXCL1 mRNA expression in VBs significantly correlated with the expression in IVD samples $(\rho=0.736 ; p=0.01)$. Out of the adipokines, only the mRNA expression of NAMPT in VBs and IVDs showed a statistically significant positive correlation ( $\rho=0.697 ; p=0.025)$. Lastly, RANKL mRNA was also found to have a strong and significant correlation between VB and IVD tissue in the infection group $(\rho=0.704 ; p=0.034)$. None of the other tested genes showed a relevant or statistically significant correlation.

In the fracture group, no significant positive correlations in VBs and IVDs were detected. However, ADAMTS4, CCL20 and LEPR mRNA expressions revealed a strong and negative correlation between IVDs and VBs $(\rho=-0.800 ; \rho=-0.800$ and $\rho=-0.738$; all $p>0.05$ ). A positive but not statistically significant, correlation was seen in the mRNA expression of CXCL5 in IVDs and VBs $(\rho=0.8 ; p=0.2)$.

\section{Discussion}

14 patients with confirmed $\mathrm{VO}$ and 14 control patients with burst fractures of the thoraco-lumbar spine were prospectively included in the present study to compare the mRNA expression in tissue samples from IVDs and adjacent VBs. The induction of the proinflammatory (adipo-)cytokines IL8, CCL20 and LEPR was detected in infected IVDs and VBs, as well as mRNA expression regulation of genes involved in bone and disc metabolism, such as mPEGS1, ADAMTS4 and RANK/RANKL/OPG. An increase in the RANKL/OPG and the RANK/OPG ratios was

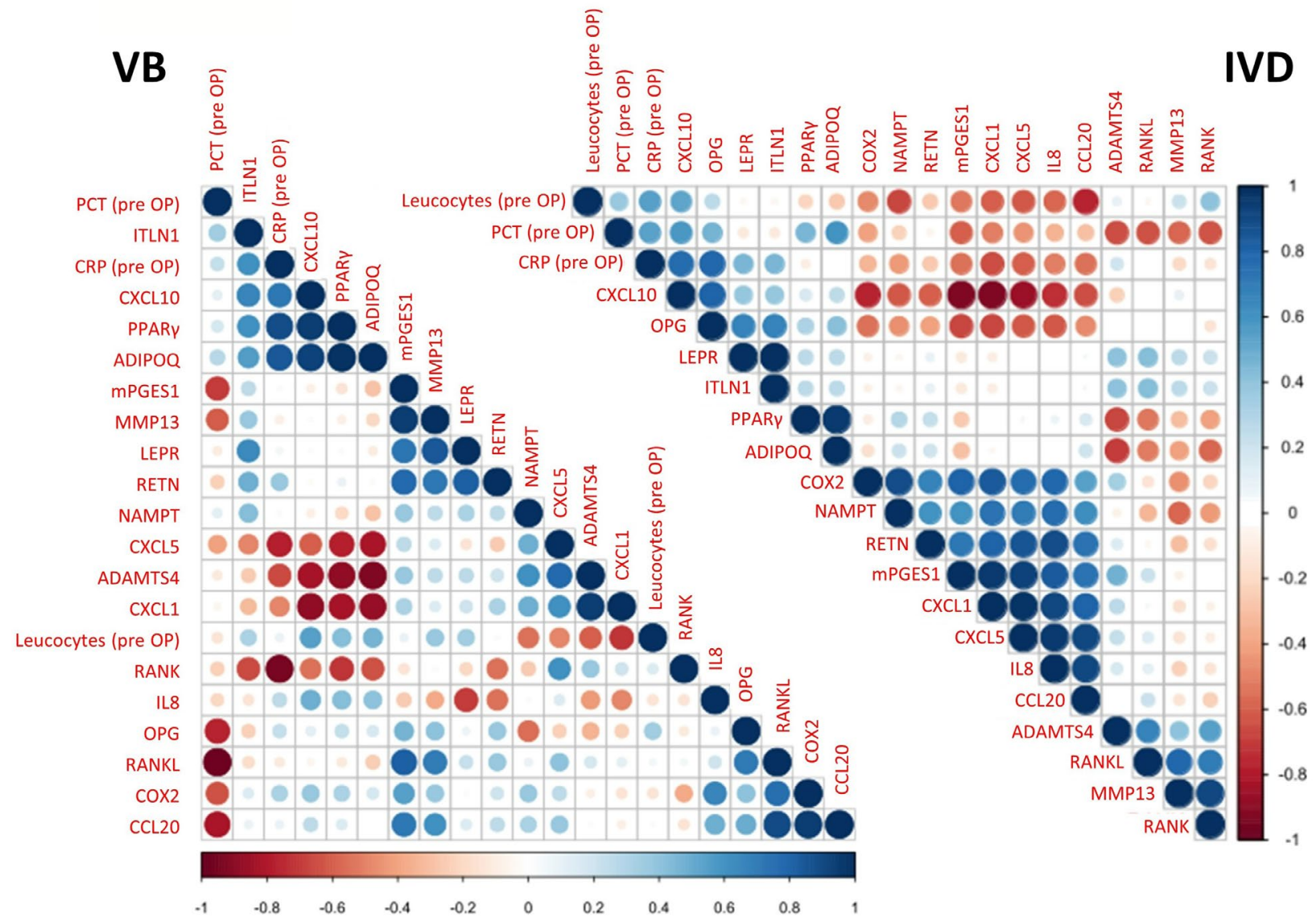

Fig. 5. Correlogram illustrating the correlations between mRNA expression levels and preoperative clinical parameters by tissue type (bone, lower left; disc, upper right). Positive correlations are depicted in blue, negative correlations in red. Colour intensity and size of the circle are proportional to the correlation coefficients. 
identified in VBs and IVDs of VO patients compared to fracture patients. Results suggested hypothetical regulatory pathways leading to tissue degradation in bacterial VO. These observations provided a first step to disclose a potential common link between pathogen defence, dysregulated inflammation and tissue degradation in human VBs and IVDs under VO conditions. This finding has not been shown before and might provide new insights into the pathomechanism of pyogenic VO.

The $R A N K / R A N K L / O P G$ axis is a central part of the molecular mechanisms of bone destruction in osteomyelitis (Mbalaviele et al., 2017). On the other hand, the mechanisms leading to the destruction of the IVD still have to be clarified. Significant bone loss in osteomyelitis can be explained by an increase in RANKL activity, which is, after binding to its signalling receptor $R A N K$, likely to trigger osteoclastinduced bone resorption and bone destruction (Lio et al., 2012; Montonen et al., 2006; Wada et al., 2006). It must be noted that $R A N K L$ is not only produced by resident bone cells, but also by activated $T$ lymphocytes (Anderson et al., 1997; Horwood et al., 1998). Remarkably, the inflammatory cytokines IL1 $\beta$ and TNF can stimulate RANKL production by osteoblasts and T-cells and concomitantly depress OPG expression in osteoblasts (Walsh and Choi, 2014; Young et al., 2011).

$R A N K L / O P G$ ratio is considered an index of osteoclastogenic stimulus (Montonen et al., 2006). In 2013, Marriott described how bacterial infection leads to inflammatory bone loss resulting from increased formation and/or activity of boneresorbing osteoclasts (Marriott, 2013). Similarly, Sanchez demonstrated that biofilm components from clinical wound isolates of $S$. aureus induce $R A N K L$ production and increase the RANKL/OPG ratio in human osteoblasts in vitro under normal growth or osteogenic conditions (Sanchez et al., 2013). In the present translational study, an increase in RANKL/ $O P G$ and $R A N K / O P G$ ratios was identified in VBs and IVDs of VO patients compared to fracture patients. The increased ratios originated primarily from a decreased OPG mRNA expression, accompanied by a trend towards increased RANK and RANKL expression, both in VB and IVD tissue.

The present study compared two distinct spinal pathologies of $\mathrm{VO}$ and vertebral fractures. During surgical treatment, tissue from VBs and IVDs were resected, as part of the standard surgical procedure. To the authors' knowledge, there is no comparable information concerning bone metabolism and the RANK/RANKL/OPG system in vertebral fractures. However, Wang et al. (2013) reported a reduced serum RANKL/OPG ratio in a fracture group compared to a healthy control group during the first 4 weeks of intertrochanteric fractures healing in elderly patients.

Influencing variables, especially NSAIDs via the regulation of COX2 and PGE2, may interfere with infection-induced regulation of gene expression. Therefore, potential influences of anti-inflammatory drugs on the prostanoid and RANK/RANKL/OPG system must be considered (Kotake et al., 2010; Pilbeam et al., 1997). In the present study, all patients in the fracture group and the majority (10 out 14) of patients in the infection group received antiinflammatory medication pre- and post-operatively as part of the standard pain treatment. No patients with known chronic inflammatory diseases were included. This homogeneity diminished relevant drug-related gene expression differences between both groups.

The regulation of RANKL and OPG, mediated by COX2 and mPEGS1, could represent a direct connective mechanism by which bacterial infection results in bone destruction: COX2 and mPEGS1, both elevated in VBs and IVDs of the infection group are involved in PGE2 biosynthesis. Liu et al. (2005), using murine cells, reported that PGE2 stimulates osteoclastogenesis through the stimulation of RANKL production, inhibition of OPG secretion by osteoblasts and up-regulation of RANK expression in osteoclasts. Suda et al. (2004) studied the role of PGE2 in the suppression of OPG mRNA expression and showed how this regulation induces osteoclast formation. They suggested two parallel events in osteoblasts: direct enhancement of RANKL expression and suppression of OPG production mediated by PGE2. Additionally, they highlighted that the suppression of OPG production in osteoblasts seems to be more important than the induction of RANKL expression for the stimulation of osteoclastogenesis (Suda et al., 2004). These assumptions support the present study's findings of reduced OPG mRNA expressions, without significantly elevated $R A N K L$ mRNA expressions.

RANKL has been described as a target for therapeutic approaches in osteodestructive diseases. Sakrurai et al. (2003) inoculated mice with Streptococcus pyogenes, resulting in a high incidence of septic arthritis. They found that an increase in the amount of RANKL was evident in the joints of infected mice and that blocking RANKL with OPG prevented bone destruction. Similarly, Verdrengh et al. (2010) showed that inhibition of RANKL signalling in $S$. aureus-inoculated mice could prevent bone loss. Keeping this in mind, the pathological imbalance in $R A N K L / O P G$ mRNA expression in the present study suggested a potential therapeutic approach to counteract bone loss in VO by inhibition of RANKL as a basis for further experimental studies. Using an anti-RANKL antibody in an animal model might be a potential experimental set up to evaluate the role of the RANK/RANKL/OPG pathway in osteomyelitis (de Castro et al., 2019).

Circulating OPG and soluble RANKL serum levels have been discussed and suggested as potential biomarkers in different contexts (Dovio et al., 2005; Kraj et al., 2005; Moschen et al., 2005). Levels of active RANKL were found to be markedly increased in patients affected by fibrous dysplasia of the bone and highly correlated with disease burden (de Castro et 
al., 2019). Circulating OPG or soluble RANKL levels were not measured in the present study and the relation of the serum levels to local gene expressions in IVD and VB was not clear. However, this might be the subject for further clinical studies with larger cohorts shedding light on the potential of serum RANKL/OPG ratios for osteomyelitis monitoring.

Adipokines belong to a large group of cytokinelike molecules that are produced not only by adipocytes, but largely by immune cells and resident tissue cells. In certain circumstances they can amplify inflammation, immune response and tissue damage (Ouchi et al., 2011). LEPR expression was significantly elevated in IVD tissue from the infection group. Leptin is a proinflammatory cytokine that is produced by inflammatory cells and its mRNA levels can be increased by several inflammatory stimuli, including interleukins (Faggioni et al., 2001). Iliopoulus et al. (2007) demonstrated that leptin is also able to induce the synthesis of relevant MMPs involved in cartilage damage, such as MMP13. Similarly, the present study's results showed a significant positive correlation between LEPR and MMP13 mRNA expression in VB tissue of the infection group, suggesting a role of $L E P R$ at the interface between inflammatory response and tissue degradation. Moreover, similar to RANK/RANKL, leptin is known as a regulator of bone homeostasis: it has been revealed that leptin regulates bone mass through a hypothalamic relay, using two neural mediators, both acting on osteoblasts (Karsenty, 2006).

A trend towards a higher $N A M P T$ expression was observed in VBs and IVDs in the infection group. Visfatin has been proven to be involved in impaired bone remodelling through induction of proinflammatory factors and dysregulated MMP/ tissue inhibitor of MMP balance during mesenchymal stem cell differentiation (Tsiklauri et al., 2018). Results suggested that adipokines may represent the interface between the inflammation mediated by cytokines and the destruction of VBs and IVDs mediated by RANKL and MMP13, among others. Moreover, the type and level of adipokines might be considered as a potential circulating biomarkers' signature to monitor $\mathrm{VO}$ and support treatment decisions.

A further hint for a common pathomechanism of tissue degradation can be seen in the synchronous transcriptional activation of key regulatory genes in VBs and IVDs: MMP13, CXCL1, NAMPT and RANKL mRNA expression showed significant positive correlations in the infection group, whereas in the fracture group no statistically significant correlations of genes' expression in VBs and IVDs were found.

\section{Limitations}

One main limitation of the study was the demographic differences between the $\mathrm{VO}$ and the fracture group. Age-related changes in the mRNA expression of inflammatory mRNA in the older VO population due to degeneration cannot be ruled out. Although patients with documented history of osteoporosis were excluded, DEXA measurements in VO or fracture patients were not conducted. Second, the study presented a limited sample size of 14 patients in each group. Therefore, statistical evaluation must be interpreted with caution. Third, the experiments only extend to mRNA but not protein levels, which were not verified by e.g. immunohistochemistry or Western blotting. Therefore, a potential discrepancy between the mRNA expression of a gene and the according protein level cannot be ruled out. Further studies should include ELISA to quantify secreted cytokines.

It must be highlighted that the proposed mechanisms of interplay are only based on the current findings of mRNA alterations and the literature. To confirm these mechanisms, pathway analysis and inhibition models are needed.

\section{Conclusion}

The mRNA expression of various cytokines and adipokines as well as of the RANK/RANKL/OPG system in VB and IVD biopsies in pyogenic $\mathrm{VO}$ patients is dysregulated from the physiological balance favouring catabolism and inflammation. The regulation of the RANK/RANKL/OPG system seems to be a key pathomechanism in the destruction of bone and disc tissue in human pyogenic VO. The elevation of COX2 and mPEGS1 mRNA suggested a central role of PGE2 as a mediator of this mechanism, leading to bacteria-induced osteoclastogenesis. The elevation of mRNA expressions of osteoclastogenesis-enhancing chemokines IL8 and CCL20 in infected tissue supported this interpretation. A shift in the adipokine profile in VO most likely regulates the pro- and anti-inflammatory pathways that eventually favour degradation of both VB and IVD. For the first time, the present study identified common mechanisms in the pathological destruction of VBs and IVDs in $\mathrm{VO}$ patients and thereby provided potential future research approaches to develop tailored diagnostic and therapeutic methods targeting the RANK/ RANKL/OPG axis and related mediators.

\section{Acknowledgments and disclosure statements}

The authors report no conflicts of interest related to this study. The authors would like to thank Nadja Reul, Institute of Clinical Microbiology and Hygiene, Regensburg, for her excellent technical assistance.

\section{References}

Anderson DM, Maraskovsky E, Billingsley WL, Dougall WC, Tometsko ME, Roux ER, Teepe 
MC, DuBose RF, Cosman D, Galibert L (1997) A homologue of the TNF receptor and its ligand enhance T-cell growth and dendritic-cell function. Nature 390: 175-179.

Asensi V, Collazos J, Celada A, Valle Garay E (2017) Role of neutrophils apoptosis in osteomyelitis pathogenesis. Clin Microbiol 06. DOI: 10.4172/23275073.1000e139.

Bachmeier BE, Nerlich A, Mittermaier N, Weiler C, Lumenta C, Wuertz K, Boos N (2009) Matrix metalloproteinase expression levels suggest distinct enzyme roles during lumbar disc herniation and degeneration. Eur Spine J 18: 1573-1586.

Boniface K, Bak-Jensen KS, Li Y, Blumenschein WM, McGeachy MJ, McClanahan TK, McKenzie BS, Kastelein RA, Cua DJ, de Waal Malefyt R (2009) Prostaglandin E2 regulates Th17 cell differentiation and function through cyclic AMP and EP2/EP4 receptor signaling. J Exp Med 206: 535-548.

Brylka LJ, Schinke T (2019) Chemokines in physiological and pathological bone remodeling. Front Immunol 10: 2182. DOI: 10.3389/fimmu.2019.02182.

Caristi S, Piraino G, Cucinotta M, Valenti A, Loddo S, Teti D (2005) Prostaglandin E2 induces interleukin-8 gene transcription by activating C/EBP homologous protein in human T lymphocytes. J Biol Chem 280: 14433-14442.

Charlson ME, Pompei P, Ales KL, MacKenzie CR (1987) A new method of classifying prognostic comorbidity in longitudinal studies: development and validation. J Chronic Dis 40: 373-383.

Chizzolini C, Chicheportiche R, Alvarez M, de Rham C, Roux-Lombard P, Ferrari-Lacraz S, Dayer J-M (2008) Prostaglandin E2 synergistically with interleukin-23 favors human Th17 expansion. Blood 112: 3696-3703.

de Castro LF, Burke AB, Wang HD, Tsai J, Florenzano P, Pan KS, Bhattacharyya N, Boyce AM, Gafni RI, Molinolo AA, Robey PG, Collins MT (2019) Activation of RANK/RANKL/OPG pathway is involved in the pathophysiology of fibrous dysplasia and associated with disease burden. J Bone Miner Res 34: 290-294.

Dougall WC (2012) Molecular pathways: osteoclastdependent and osteoclast-independent roles of the RANKL/RANK/OPG pathway in tumorigenesis and metastasis. Clin Cancer Res 18: 326-335.

Doutchi M, Seng P, Menard A, Meddeb L, Adetchessi T, Fuentes S, Dufour H, Stein A (2015) Changing trends in the epidemiology of vertebral osteomyelitis in Marseille, France. New Microbes New Infect 7: 1-7.

Dovio A, Data V, Angeli A (2005) Circulating osteoprotegerin and soluble RANKL: do they have a future in clinical practice? J Endocrinol Invest 28: 14-22.

Faggioni R, Feingold KR, Grunfeld C (2001) Leptin regulation of the immune response and the immunodeficiency of malnutrition. FASEB J 15: 25652571.
Fairbank JC, Pynsent PB (2000) The Oswestry disability index. Spine (Phila Pa 1976) 25: 2940-2952.

Foreman SC, Schwaiger BJ, Gempt J, Jungmann PM, Kehl V, Delbridge C, Wantia N, Zimmer C, Kirschke JS (2017) MR and CT imaging to optimize CT-guided biopsies in suspected spondylodiscitis. World Neurosurg 99: 726-734.e7.

Gouliouris T, Aliyu SH, Brown NM (2010) Spondylodiscitis: update on diagnosis and management. J Antimicrob Chemother 65 Suppl 3: iii11-24.

Grammatico L, Baron S, Rusch E, Lepage B, Surer N, Desenclos JC, Besnier JM (2008) Epidemiology of vertebral osteomyelitis (VO) in France: analysis of hospital-discharge data 2002-2003. Epidemiol Infect 136: 653-660.

Horwood NJ, Elliott J, Martin TJ, Gillespie MT (1998) Osteotropic agents regulate the expression of osteoclast differentiation factor and osteoprotegerin in osteoblastic stromal cells. Endocrinology 139: 47434746.

Iliopoulos D, Malizos KN, Tsezou A (2007) Epigenetic regulation of leptin affects MMP13 expression in osteoarthritic chondrocytes: possible molecular target for osteoarthritis therapeutic intervention. Ann Rheum Dis 66: 1616-1621.

Iwata E, Scarborough M, Bowden G, McNally M, Tanaka Y, Athanasou NA (2019) The role of histology in the diagnosis of spondylodiscitis: correlation with clinical and microbiological findings. Bone Joint J 101-B: 246-252.

Jean M, Irisson JO, Gras G, Bouchand F, Simo D, Duran C, Perronne C, Mulleman D, Bernard L, Dinh A (2017) Diagnostic delay of pyogenic vertebral osteomyelitis and its associated factors. Scand J Rheumatol 46: 64-68.

Josse J, Velard F, Gangloff SC (2015) Staphylococcus aureus vs. osteoblast: relationship and consequences in osteomyelitis. Front Cell Infect Microbiol 5: 85. DOI: $10.3389 /$ fcimb.2015.00085.

Karsenty G (2006) Convergence between bone and energy homeostases: leptin regulation of bone mass. Cell Metab 4: 341-348.

Kepler CK, Ponnappan RK, Tannoury CA, Risbud MV, Anderson DG (2013) The molecular basis of intervertebral disc degeneration. Spine J 13: 318-330.

Kim CJ, Kang SJ, Choe PG, Park WB, Jang HC, Jung SI, Song KH, Kim ES, Kim HB, Oh MD, Park KH, Kim NJ (2015) Which tissues are best for microbiological diagnosis in patients with pyogenic vertebral osteomyelitis undergoing needle biopsy? Clin Microbiol Infect 21: 931-935.

Klawitter M, Hakozaki M, Kobayashi H, Krupkova O, Quero L, Ospelt C, Gay S, Hausmann O, Liebscher T, Meier U, Sekiguchi M, Konno S, Boos N, Ferguson SJ, Wuertz K (2014) Expression and regulation of tolllike receptors (TLRs) in human intervertebral disc cells. Eur Spine J 23: 1878-1891.

Kong YY, Boyle WJ, Penninger JM (2000) Osteoprotegerin ligand: a regulator of immune 
responses and bone physiology. Immunol Today 21: 495-502.

Kostenuik PJ (2005) Osteoprotegerin and RANKL regulate bone resorption, density, geometry and strength. Curr Opin in Pharmacol 5: 618-625.

Kotake S, Yago T, Kawamoto M, Nanke Y (2010) Effects of NSAIDs on differentiation and function of human and murine osteoclasts - crucial 'human osteoclastology.' Pharmaceuticals (Basel) 3: 13941410.

Kouijzer IJE, Scheper H, de Rooy JWJ, Bloem JL, Janssen MJR, van den Hoven L, Hosman AJF, Visser LG, Oyen WJG, Bleeker-Rovers CP, de Geus-Oei L-F (2018) The diagnostic value of 18F-FDG-PET/ CT and MRI in suspected vertebral osteomyelitis - a prospective study. Eur J Nucl Med Mol Imaging 45: 798-805.

Kraj M, Owczarska K, Sokołowska U, Centkowski P, Pogłód R, Kruk B (2005) Correlation of osteoprotegerin and sRANKL concentrations in serum and bone marrow of multiple myeloma patients. Arch Immunol Ther Exp (Warsz) 53: 454-464.

Lio P, Paoletti N, Moni M, Atwell K, Merelli E, Viceconti M (2012) Modelling osteomyelitis. BMC Bioinformatics 13 Suppl 14: S12. DOI: 10.1186/1471-2105-13-S14-S12.

Liu X-H, Kirschenbaum A, Yao S, Levine AC (2005) Cross-talk between the interleukin- 6 and prostaglandin $\mathrm{E}(2)$ signaling systems results in enhancement of osteoclastogenesis through effects on the osteoprotegerin/receptor activator of nuclear factor $-\kappa B$ (RANK) ligand/RANK system. Endocrinology 146: 1991-1998.

Loibl M, Stoyanov L, Doenitz C, Brawanski A, Wiggermann P, Krutsch W, Nerlich M, Oszwald M, Neumann C, Salzberger B, Hanses F (2014) Outcome-related co-factors in 105 cases of vertebral osteomyelitis in a tertiary care hospital. Infection 42: 503-510.

Mannion AF, Porchet F, Kleinstück FS, Lattig F, Jeszenszky D, Bartanusz V, Dvorak J, Grob D (2009) The quality of spine surgery from the patient's perspective. Part 1: the core outcome measures index in clinical practice. Eur Spine J 18 Suppl 3: 367-373.

Marriott I (2013) Apoptosis-associated uncoupling of bone formation and resorption in osteomyelitis. Front Cell Infect Microbiol 3: 101. DOI: 10.3389/ fcimb.2013.00101.

Mbalaviele G, Novack DV, Schett G, Teitelbaum SL (2017) Inflammatory osteolysis: a conspiracy against bone. J Clin Invest 127: 2030-2039.

Meghji S, Crean SJ, Hill PA, Sheikh M, Nair SP, Heron K, Henderson B, Mawer EB, Harris M (1998) Surface-associated protein from Staphylococcus aureus stimulates osteoclastogenesis: possible role in $S$. aureus-induced bone pathology. Br J Rheumatol 37: 1095-1101.

Millward-Sadler SJ, Costello PW, Freemont AJ, Hoyland JA (2009) Regulation of catabolic gene expression in normal and degenerate human intervertebral disc cells: implications for the pathogenesis of intervertebral disc degeneration. Arthritis Res Ther 11: R65. DOI: 10.1186/ar2693.

Montonen M, Li T-F, Lukinmaa P-L, Sakai E, Hukkanen M, Sukura A, Konttinen YT (2006) RANKL and cathepsin $\mathrm{K}$ in diffuse sclerosing osteomyelitis of the mandible. J Oral Pathol Med 35: 620-625.

Moschen AR, Kaser A, Stadlmann S, Millonig G, Kaser S, Mühllechner P, Habior A, Graziadei I, Vogel W, Tilg H (2005) The RANKL/OPG system and bone mineral density in patients with chronic liver disease. J Hepatol 43: 973-983.

Mylona E, Samarkos M, Kakalou E, Fanourgiakis P, Skoutelis A (2009) Pyogenic vertebral osteomyelitis: a systematic review of clinical characteristics. Semin Arthritis and Rheum 39: 10-17.

Nakashima T, Takayanagi H (2009) Osteoimmunology: crosstalk between the immune and bone systems. J Clin Immunol 29: 555-567.

Okahashi N, Sakurai A, Nakagawa I, Fujiwara T, Kawabata S, Amano A, Hamada S (2003) Infection by Streptococcus pyogenes induces the receptor activator of NF- $\kappa$ B ligand expression in mouse osteoblastic cells. Infect Immun 71: 948-955.

Okamoto K, Nakashima T, Shinohara M, NegishiKoga T, Komatsu N, Terashima A, Sawa S, Nitta T, Takayanagi H (2017) Osteoimmunology: the conceptual framework unifying the immune and skeletal systems. Physiol Rev 97: 1295-1349.

Ouchi N, Parker JL, Lugus JJ, Walsh K (2011) Adipokines in inflammation and metabolic disease. Nat Rev Immunol 11: 85-97.

Pathak JL, Bakker AD, Verschueren P, Lems WF, Luyten FP, Klein-Nulend J, Bravenboer N (2015) CXCL8 and CCL20 enhance osteoclastogenesis via modulation of cytokine production by human primary osteoblasts. PLoS One 10: e0131041. DOI: 10.1371/journal.pone.0131041.

Pilbeam CC, Fall PM, Alander CB, Raisz LG (1997) Differential effects of nonsteroidal anti-inflammatory drugs on constitutive and inducible prostaglandin G/H synthase in cultured bone cells. J Bone Mineral Res 12: 1198-1203.

Reischl U, Linde HJ, Metz M, Leppmeier B, Lehn N (2000) Rapid identification of methicillin-resistant Staphylococcus aureus and simultaneous species confirmation using real-time fluorescence PCR. J Clin Microbiol 38: 2429-2433.

Sakurai A, Okahashi N, Nakagawa I, Kawabata S, Amano A, Ooshima T, Hamada S (2003) Streptococcus pyogenes infection induces septic arthritis with increased production of the receptor activator of the NF- $\kappa$ B ligand. Infect Immun 71: 6019-6026.

Sanchez CJ, Ward CL, Romano DR, Hurtgen BJ, Hardy SK, Woodbury RL, Trevino AV, Rathbone CR, Wenke JC (2013) Staphylococcus aureus biofilms decrease osteoblast viability, inhibits osteogenic differentiation, and increases bone resorption in vitro. BMC Musculoskelet Disord 14: 187. DOI: 10.1186/1471-2474-14-187.

Sano T, Akeda K, Yamada J, Takegami N, Sudo T, Sudo A (2019) Expression of the RANK/RANKL/ 
OPG system in the human intervertebral disc: implication for the pathogenesis of intervertebral disc degeneration. BMC Musculoskelet Disord 20: 225. DOI: 10.1186/s12891-019-2609-x.

Somayaji SN, Ritchie S, Sahraei M, Marriott I, Hudson MC (2008) Staphylococcus aureus induces expression of receptor activator of $N F-\kappa B$ ligand and prostaglandin E2 in infected murine osteoblasts. Infect Immun 76: 5120-5126.

Suda K, Udagawa N, Sato N, Takami M, Itoh K, Woo J-T, Takahashi N, Nagai K (2004) Suppression of osteoprotegerin expression by prostaglandin E2 is crucially involved in lipopolysaccharide-induced osteoclast formation. J Immunol 172: 2504-2510.

Takegami N, Akeda K, Yamada J, Sano T, Murata K, Huang J, Masuda K, Sudo A (2017) RANK/ RANKL/OPG system in the intervertebral disc. Arthritis Res Ther 19: 121. DOI: 10.1186/s13075-0171332-y.

Tsiklauri L, Werner J, Kampschulte M, Frommer KW, Berninger L, Irrgang M, Glenske K, Hose D, El Khassawna T, Pons-Kühnemann J, Rehart S, Wenisch S, Müller-Ladner U, Neumann E (2018) Visfatin alters the cytokine and matrix-degrading enzyme profile during osteogenic and adipogenic MSC differentiation. Osteoarthritis Cartilage 26: 1225-1235.

Verdrengh M, Bokarewa M, Ohlsson C, Stolina M, Tarkowski A (2010) RANKL-targeted therapy inhibits bone resorption in experimental Staphylococcus aureus-induced arthritis. Bone 46: 752-758.

Wada T, Nakashima T, Hiroshi N, Penninger JM (2006) RANKL-RANK signaling in osteoclastogenesis and bone disease. Trends Mol Med 12: 17-25.

Walsh MC, Choi Y (2014) Biology of the RANKLRANK-OPG system in immunity, bone, and beyond. Front Immunol 5: 511. DOI: 10.3389/ fimmu.2014.00511.

Wang X-F, Zhang Y-K, Yu Z-S, Zhou J-L (2013) The role of the serum RANKL/OPG ratio in the healing of intertrochanteric fractures in elderly patients. Mol Med Rep 7: 1169-1172.

Widaa A, Claro T, Foster TJ, O’Brien FJ, Kerrigan SW (2012) Staphylococcus aureus protein A plays a critical role in mediating bone destruction and bone loss in osteomyelitis. PLoS One 7e40586. DOI: 10.1371/journal.pone.0040586.

Young AB, Cooley ID, Chauhan VS, Marriott I (2011) Causative agents of osteomyelitis induce death domain-containing TNF-related apoptosis-inducing ligand receptor expression on osteoblasts. Bone 48: 857-863.

\section{Web Reference}

1. https://www.promega.de/resources/protocols/ technical-manuals/0/pgem-t-and-pgem-t-easyvector-systems-protocol/ [20.10.2021]

\section{Discussion with Reviewer}

Reviewer: While the VB is a well-vascularised tissue, the IVD has much less vascularisation. Would you have expected different expression profiles of the various cytokines, adipokines?

Authors: The physiological vascularisation of the IVD and VB differs distinctly. However, during inflammation, neoangiogenesis is triggered in the IVD, where numerous cytokines have been detected, at least in a degenerative setting (Liu et al., 2021, additional reference). More importantly, gene expression, as opposed to soluble mediators, was measured, indicating that the presence of resident cells that can be transactivated by infection is probably more crucial than their supply by blood and lymph vessels. Regarding adipokines, disc cells express adipokines, e.g. leptin (Zhao et al., 2008, additional reference), and the role of adipokines in disc degeneration has been shown (Sharma, 2018, additional reference). Therefore, the expression of adipokines does not seem to depend principally on the extent of vascularisation. For this reason, the same set of target genes was chosen to be evaluated in IVDs and VBs. For adipokines and cytokines, roughly similar expression profiles were expected and those profiles were shown for the first time in VO. The similar expression pattern of RANK/RANKL/ $O P G$ in the IVD and VB tissue was most unexpected. Although this system, which is mainly linked to bone metabolism, has been hypothesised to be also involved in IVD degeneration (Sano et al., 2019), it was unexpected to find comparable expressions in VBs and IVDs in VO patients.

\section{Additional References}

Liu C, Liang G, Deng Z, Tan J, Zheng Q, Lyu F-J (2021) The upregulation of COX2 in human degenerated nucleus pulposus: the association of inflammation with intervertebral disc degeneration. Mediators Inflamm 2021: 2933199. DOI $10.1155 / 2021 / 2933199$.

Sharma A (2018) The role of adipokines in intervertebral disc degeneration. Med Sci (Basel) 6: E34. DOI: 10.3390/medsci6020034.

Zhao C-Q, Liu D, Li H, Jiang L-S, Dai L-Y (2008) Expression of leptin and its functional receptor on disc cells: contribution to cell proliferation. Spine 33: E858. DOI: 10.1097/BRS.0b013e31818338e5.

Editor's note: The Scientific Editor responsible for this paper was Fintan Moriarty. 